\title{
A lovastatin-elicited genetic program inhibits M2 macrophage polarization and enhances $T$ cell infiltration into spontaneous mouse mammary tumors
}

\author{
Emilia Mira ${ }^{1}$, Lorena Carmona-Rodríguez ${ }^{1}$, Manuel Tardáguila ${ }^{1}$, Iñigo Azcoitia ${ }^{2}$, \\ Alicia González-Martínn ${ }^{1,4}$, Luis Almonacid ${ }^{1}$, Josefina Casas $^{3}$, Gemma Fabriás ${ }^{3}$, \\ Santos Mañes ${ }^{1}$ \\ ${ }^{1}$ Department of Immunology and Oncology, Centro Nacional de Biotecnología/CSIC, Madrid, Spain, \\ 2 Department of Cell Biology, School of Biology, Universidad Complutense de Madrid, Madrid, Spain, \\ ${ }^{3}$ Department of Biomedicinal Chemistry, Catalan Institute of Advanced Chemistry/CSIC, Barcelona, Spain \\ ${ }^{4}$ Present address: The Scripps Research Institute, Department of Immunology and Microbial Science, La Jolla, CA \\ Correspondence to: Santos Mañes, email: smanes@cnb.csic.es
}

Emilia Mira, email: emira@cnb.csic.es

Keywords: inflammation, tumor immunity, macrophage polarization, angiogenesis, vascular normalization, myeloid infiltration, lymphoid infiltration, statins

Received: September 05, 2013 Accepted: October 24, $2013 \quad$ Published: October 26, 2013

This is an open-access article distributed under the terms of the Creative Commons Attribution License, which permits unrestricted use, distribution, and reproduction in any medium, provided the original author and source are credited.

\section{ABSTRACT:}

Beyond their ability to inhibit cholesterol biosynthesis, the statins have pleiotropic effects that include anti-inflammatory and immunomodulatory activities. Statins could have clinical utility, alone or in combination with other chemotherapeutics, in the treatment of cancer. The mechanisms that underlie the anti-tumor activity of the statins are nonetheless poorly defined. No studies have analyzed how they alter the tumor-associated leukocyte infiltrate, a central factor that influences tumor stroma and cancer evolution. Here we used HER2/neu transgenic ( $\mathrm{Tg}-\mathrm{neu}$ ) mice to analyze the effect of lovastatin (Lov) on the inflammatory reaction of spontaneous mammary tumors. Lov treatment of tumor-bearing Tg-neu mice did not alter growth of established tumors, but significantly reduced the number of new oncogenic lesions in these mice. Moreover, Lov inhibited the growth of newly implanted Tg-neu tumors in immunocompetent but not in immunodeficient mice. We found that Lov enhanced tumor infiltration by effector $\mathbf{T}$ cells, and reduced the number of immunosuppressive and pro-angiogenic M2-like tumor-associated macrophages (TAM). Concomitantly, the drug improved the structure and function of the tumor vasculature, measured as enhanced tumor oxygenation and penetration of cytotoxic drugs. Microarray analysis identified a Lov-elicited genetic program in Tg-neu tumors that might explain these effects; we observed Lov-induced downregulation of placental growth factor, which triggers aberrant angiogenesis and M2-like TAM polarization. Our results identify a role for lovastatin in the shaping and re-education of the inflammatory infiltrate in tumors, with functional consequences in angiogenesis and antitumor immunity.

\section{INTRODUCTION}

The progression or inhibition of a tumor is intimately linked to the integration of complex signals delivered from its microenvironment. Evidence indicates that immune cells in the tumor vicinity are major regulators of the outcome. Tumor infiltration by cells of the adaptive immune arm is associated with good prognosis in glioblastoma, colon and ovarian cancers [1-
3]; in contrast, massive accumulation of cells of the innate immune system, particularly macrophages, is linked to poor prognosis [4-7]. Tumor-associated macrophages (TAM) nonetheless have contrasting activities, depending on their differentiation state. Progressing tumors skew TAM differentiation towards an alternatively activated (M2-like) state that induces angiogenesis and aids tumor cell evasion of antitumor immunity. In non-progressing or regressing tumors, however, TAM tend to a classic, pro- 
inflammatory (M1-like) program that promotes adaptive immune responses and tumor lysis $[5,6]$. The ability to regulate the type of inflammatory infiltrate as well as its differentiation program is thus central to the way that inflammation affects tumor evolution.

Given the strong influence of inflammation on tumor biology, anti-inflammatory drugs are being screened for antitumor activity. The statins are a family of inhibitors of the 3-hydroxy-3-methylglutaryl coenzyme A (HMG$\mathrm{CoA}$ ) reductase enzyme, which converts acetyl-CoA into mevalonic acid. Since HMG-CoA reductase catalyzes the rate-limiting step in the mevalonate pathway of cholesterol biosynthesis in the liver, it was thought that the major clinical benefit of statins was to reduce cholesterol levels in the bloodstream [8]; statins are thus in wide clinical use for the prevention and treatment of cardiovascular disease [9]. Nonetheless, mevalonate is also the precursor of isoprenoid compounds, which are substrates for posttranslational modification of many proteins involved in cell signaling. Blockade of isoprenoid synthesis might explain the pleiotropic effects reported for statins in extrahepatic tissues, including inhibition of pathogen infection as well as anti-inflammatory and immunomodulatory activities [10-15].

Many studies indicate that statins might also have anti-tumorigenic activity, including inhibition of angiogenesis $[16,17]$ and direct cytotoxicity of tumor cells [18-20]. Breast cancer cells bearing mutated p53 upregulate the mevalonate pathway to disrupt mammary acinar morphology and promote tumorigenesis, suggesting that statins can be useful for tumors with mutations in this suppressor gene [21]. Although these studies and some epidemiological analyses suggest a preventive role for statins in human cancer, randomized clinical trials indicate that statins are not potent anti-cancer agents in monotherapy-based regimes (reviewed in [22]). Statins can also potentiate other cytotoxic drugs [23-25], however, which prompted a number of ongoing phase I/II clinical trials to test whether statins improve chemotherapeutic effectiveness of other anti-cancer drugs in skin (NCT00966472), gastric (NCT01099085), prostate (NCT01220973), and breast cancers (NCT00354640) (http://www.clinicaltrials.gov). The mechanisms that underlie statin synergy with cytotoxic drugs are diverse and not fully known. Statins overcome tumor cell resistance to cytotoxic drugs by targeting multidrug resistance-associated proteins, and alleviate the secondary effects of chemotherapy in kidney and heart (reviewed in [25]). Recent evidence suggests that statins increase penetration of cytotoxic compounds into the tumor by regulating endothelial nitric oxide (NO) synthesis and oxidative stress; this in turn normalizes tumor blood vessel morphology, maturation and function [26]. Statins nonetheless induce pericyte apoptosis in vitro [27]; this apparent contradiction implies complexity in the way statins alter the tumor vasculature.
Although a major pleiotropic activity of statins is the regulation of immune and inflammatory responses, the relevance of these statin-mediated effects in cancer has not been studied in detail. Pravastatin was reported to downregulate expression of pro-inflammatory and pro-angiogenic factors, which correlated with tumor growth inhibition in syngeneic mice [17]. In experimental models of autoimmunity and chronic inflammation, statins provoke a shift in $\mathrm{T}$ cell polarization towards a Th2 phenotype, and increase regulatory $\mathrm{T}$ (Treg) cell differentiation and recruitment (reviewed in [14]. These activities could be thought to have a negative impact on the potential immune response to tumors, and thus promote oncogenesis and tumor progression. Whether statin treatment impairs immune function in tumor models has not been reported.

We administered the natural statin lovastatin (Lov) to transgenic FVB/N-Tg(MMTVneu) mice (Tg-neu), which overexpress the HER2/neu proto-oncogene and develop spontaneous mammary tumors. Compared to tumor graft models, in which implantation causes tissue damage and hence inflammation, $\mathrm{Tg}$-neu tumors generate an inflammatory response that better resembles that of sporadic human tumors. Tg-neu mice develop an immune response to neu antigen, which is functionally suppressed as in human tumors [28]; the residual neu-specific T cell repertoire can be reactivated to restrict tumor growth [29]. We found that Lov treatment of tumor-bearing Tgneu mice did not alter growth of established tumors, but significantly reduced the onset of new oncogenic lesions. Lov inhibited TAM polarization toward a pro-tumorigenic M2-like phenotype and increased T cell infiltration into the tumor. These changes paralleled the stabilization of tumor blood vessel structure; indeed, Lov treatment reduced tumor hypoxia and enhanced doxorubicin penetration into Tg-neu tumors. Expression profiling identified a genetic program elicited by Lov treatment in these tumors, which included downregulation of placental growth factor (PlGF), an inducer of vasculature abnormalization as well as M2-like TAM polarization in tumors [30]. These combined Lov activities might create a hostile inflammatory environment for the tumor, in which antitumor immunity dominates over immune evasion, explaining the reduced tumor multiplicity in Lov-treated Tg-neu mice.

\section{RESULTS}

\section{Lovastatin treatment does not alter growth of established tumors but reduces appearance of new lesions}

Transgenic FVB/N-Tg(MMTVneu) mice (Tg-neu), which overexpress the neu protoncogene in the mammary 
gland and develop spontaneous mammary tumors, were randomly assigned for treatment with vehicle (Vhcl) or Lov as soon as lumps were detected by palpation (Fig. 1A). The Lov dose used (10 mg/Kg every 3 days, i.p.) is comparable to that for humans treated with $40 \mathrm{mg}$ /day [31].

In this model, Lov injection did not affect growth kinetics of primary tumors (Fig. 1B) or their weight at endpoint (Fig. 1C) compared to Vhcl treatment. Immunohistochemical analysis showed no differences in the apoptotic cell fraction between Vhcl- and Lov-treated tumors (Fig. 1D; TUNEL ${ }^{+}$cells/field, $0.37 \pm 0.01$ Vhcl vs. $0.29 \pm 0.01$ Lov, $\mathrm{p}=0.7 ; n=6$ /group). Although we generally noted a slight reduction in the proliferating cell fraction (phosphohistone $\mathrm{H} 3 ; \mathrm{p}-\mathrm{H}_{3}^{+}$) in tumors from Lovtreated mice, these differences were not significant (Fig. $1 \mathrm{E}, \mathrm{F} ; \mathrm{p}=0.5, n=6$ /group). Macroscopic lung metastases were not detected in these mice.

Tg-neu-treated mice initially developed focal adenocarcinomas; multifocal lesions nonetheless appeared at longer latency periods. Although Lov treatment did not impair growth of the primary tumor, it significantly reduced tumor multiplicity (mean number of affected glands/mouse) compared to controls (Fig. 1G). At 6 weeks after initial lump detection, $100 \%$ of Vhcl-treated mice showed tumors in at least two mammary glands and $25 \%$ developed tumors in up to six; in contrast, $46 \%$ of Lov-treated mice had only one affected mammary gland, with a maximum of lesions in three glands $(30 \%$ of the mice). Treatment of sporadic mammary tumors with high/ medium Lov doses thus did not reduce tumor growth, but precluded promotion of new oncogenic lesions in the mammary gland.

\section{Lovastatin potentiates tumor chemotherapy by increasing drug delivery into tumors}

Statins can enhance the activity of several cytotoxic drugs, including the anthracyclins [25]. We thus tested
A

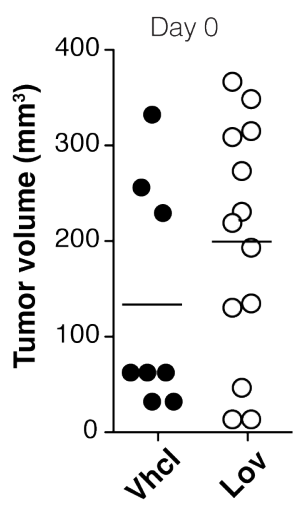

D TUNEL (green)
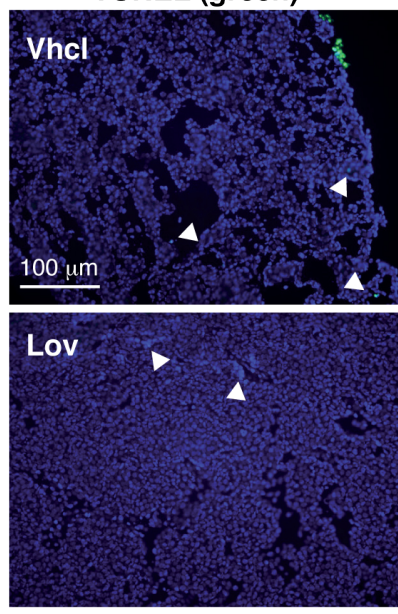

B

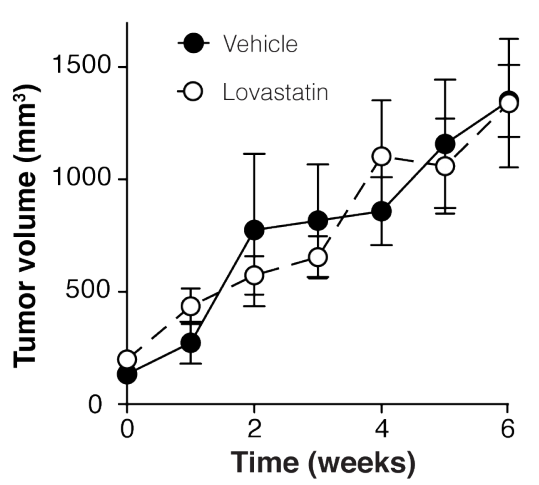

E $\quad \mathrm{p}\left(\mathbf{S}^{10}\right)$-Histone $\mathrm{H3}(\mathrm{red})$

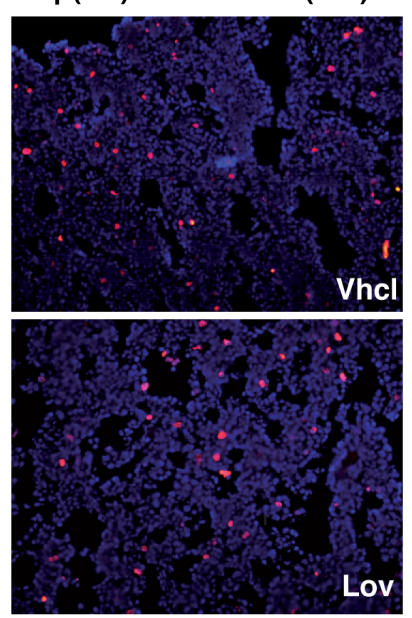

C

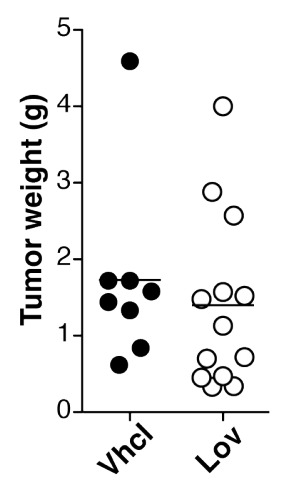

$\mathbf{F}$

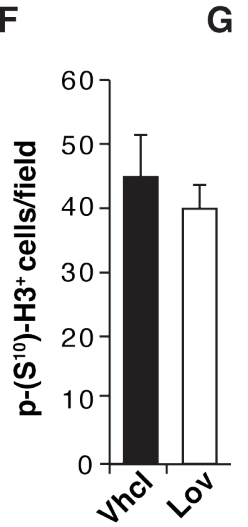

G

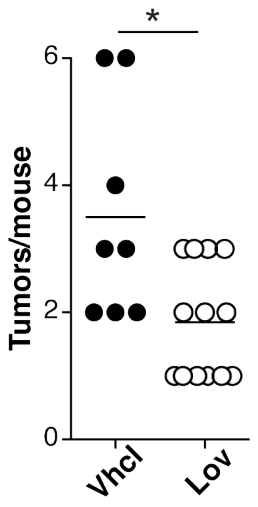

Figure 1: Lovastatin reduces tumor multiplicity in Tg-neu mice. Tg-neu mice were assigned for Vhcl or Lov treatment after lump detection ( $n=8$, Vhcl; $n=11$, Lov). (A) Volume of individual tumors at treatment onset. (B) Growth kinetics of primary Tg-neu tumors in Vhcl- or Lov-treated mice. (C) Weight of each initial tumor after sacrifice. (D, E) Representative images of sections from the initial tumor, stained for TUNEL (D) and $\mathrm{p}-\mathrm{H}^{+}(\mathrm{E})$; bar $=100 \mu \mathrm{m}$. (F) Quantification of images in $E$ ( $n=15$ sections from 5 tumors/group; $\mathrm{p}=0.35$, Mann-Whitney test). (G) Tumor number for each mouse. ${ }^{*} \mathrm{p}<0.05$, two-tailed Student's $t$-test. 
whether Lov intensified the chemotherapeutic activity of doxorubicin (Doxo) in mice with spontaneous Tgneu mammary tumors. Tg-neu tumors treated with a suboptimal Doxo dose $(0.5 \mathrm{mg} / \mathrm{Kg}$, twice weekly) or with Lov alone showed rapid growth despite treatment (Fig. 2A). Co-administration of Doxo $(0.5 \mathrm{mg} / \mathrm{Kg})+\mathrm{Lov}$ significantly inhibited tumor growth at levels comparable to those found after $2.5 \mathrm{mg} / \mathrm{Kg}$ Doxo administration (Fig. 2A). In addition, Doxo+Lov treatment significantly reduced tumor multiplicity in Tg-neu mice (Fig. 2B).

The Lov-induced enhancement of Doxo chemotherapeutic activity might be due to potentiation of Doxo cytotoxic activity or to increased Doxo perfusion into the tumor parenchyma. To explore the latter hypothesis, we used high-performance liquid chromatography coupled with fluorescence detection (HPLC-FD) to analyze Doxo levels in extracts of tumors treated with Doxo $(0.5 \mathrm{mg} / \mathrm{Kg})+\mathrm{Vhcl}$ or $+\mathrm{Lov}$, using daunorubicin as an internal standard (Fig. 2C). Compared to Vhcl treatment, Lov co-administration significantly enhanced Doxo levels in tumors (Fig. 2D). Lov thus increased chemotherapy efficiency by improving delivery of this drug into the tumor.
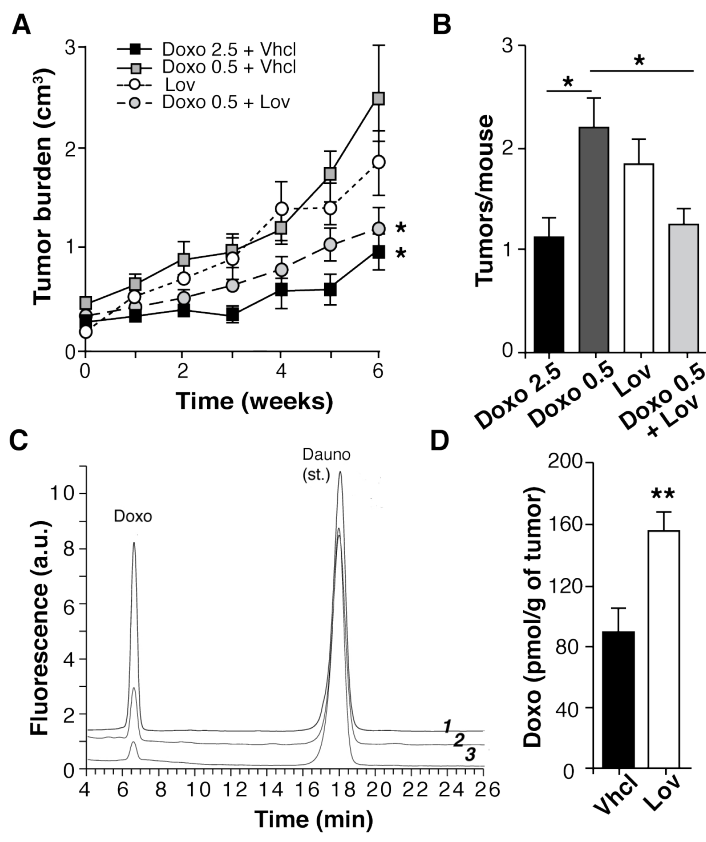

Figure 2: Lovastatin improves doxorubicin chemotherapy in Tg-neu mice. (A) Growth kinetics of spontaneous Tg-neu tumors treated with Lov, Doxo+Vhcl or Doxo+Lov ( $n=10 /$ group; $*$, significant differences with the Doxo $0.5+$ Vhcl-treated group $(\mathrm{p}<0.05$, repeated measures ANOVA with Dunnett post-test). (B) Mean tumor number in mice from $A$ ( $\mathrm{p}<0.05$, one-way ANOVA with Dunnet post-test). (C) HPLC-FD profiles of a tissue extract containing Doxo and daunorubicin standards (1), and representative tumor samples from mice treated with $0.5 \mathrm{mg} / \mathrm{Kg}$ Doxo+Lov (2) or Doxo+Vhcl (3). (D) Doxo quantification in samples from $C(n=6$; **p $<0.01$ Mann-Whitney test).

\section{Lovastatin restores correct structure to tumor vasculature}

Improved drug perfusion into tumors is associated with changes in tumor blood vessel structure and function; we thus tested whether Lov treatment affected angiogenesis in our model. Histochemical analysis showed clear differences in the number and morphology of CD $31^{+}$ tumor blood vessels after Lov treatment (Fig. 3A). Vessels in Vhcl-treated tumors were less abundant (Fig. 3B) and their diameter was heterogeneous (Fig. 3C) compared to those in Lov-treated tumors, which were longer and thinner (Fig. 3C). Reduced vessel diameter in Lovtreated tumors compared to controls was also observed by scanning electron microscopy (SEM) (Fig. 3D, E). Ultrastructural analysis of Vhcl-treated tumors showed many of the phenotypic abnormalities of endothelial cells (EC) described in other tumor models, including irregular borders and discontinuities or gaps in the EC layer (Fig. $3 F, G)$, which suggests EC hyperactivity. This contrasted with the regular, continuous, tightly packed EC in Lovtreated tumors (Fig. 3H, I), which lend an appearance of "smoothness" to the vessel lumen.

\section{Lovastatin increases pericyte coverage and tumor perfusion}

Morphological irregularities in EC are often associated to poor coverage by mural cells [32]. Staining for CD31 and the intermediate filament nestin showed that Lov treatment significantly enhanced mural cell coverage (Fig. 3J, K). Analysis of tumor sections from mice perfused with FITC-lectin showed that Lov treatment also increased the percentage of vessels that double-stained for lectin and CD31 compared to controls (Fig. 3L-N). Lov treatment therefore improved tumor perfusion, probably by increasing vessel stability and maturation.

\section{Lovastatin improves tumor oxygenation}

Enhanced perfusion and increased blood vessel number should improve oxygenation of Lov-treated tumors. Hematoxylin/eosin staining showed that tumors from Vhcl-treated mice had large necrotic areas, which were not observed in those treated with Lov (Fig. 4A). Necrotic regions also showed enhanced autofluorescence (Fig. 4A); the extension of these fluorescent areas was significantly smaller in Lov-treated tumors (Fig. 4B). "Blood lakes", which are associated with impaired vessel function and oxygenation [33], were usually found near the necrotic areas (Fig. 4A, arrowheads).

To further study tumor oxygenation, Vhcl- and Lovtreated mice received injections of the hypoxia marker pimonidazole (Fig. 4C). Pimonidazole-stained areas were 

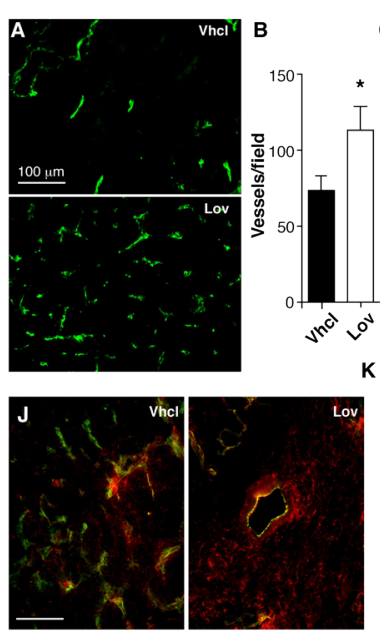

C
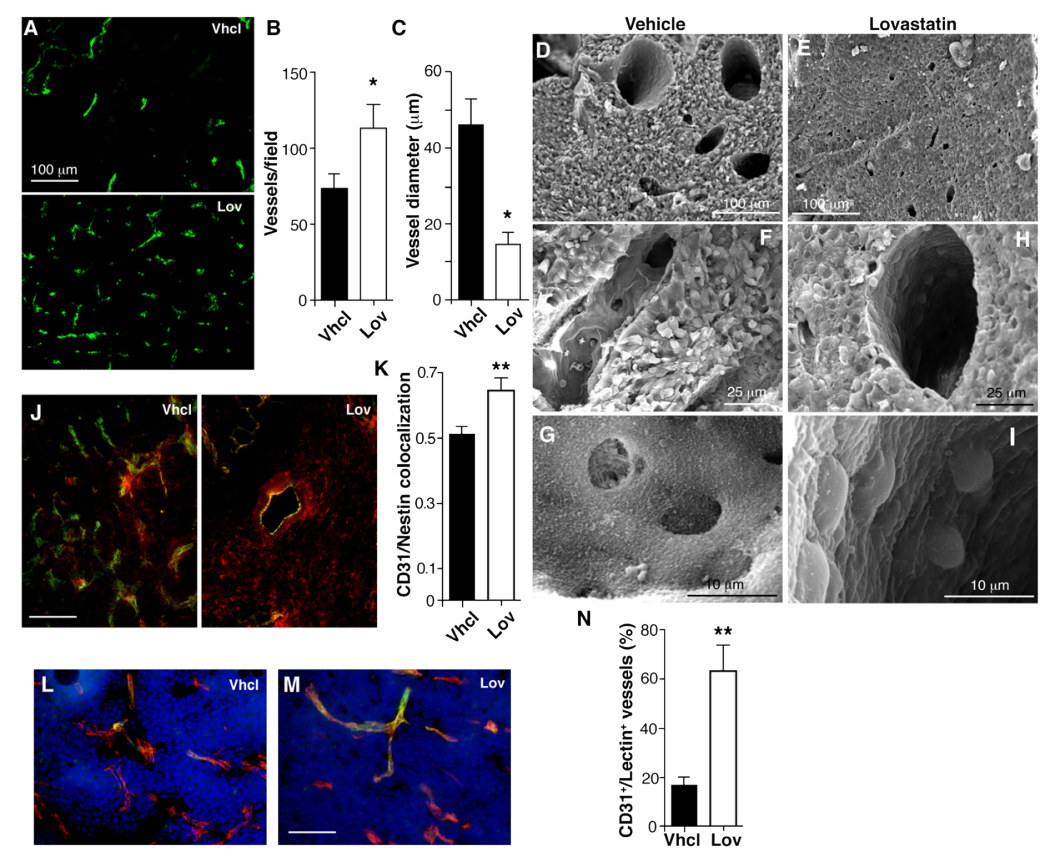

Figure 3: Lovastatin regulates Tg-neu tumor vascular phenotype. (A) Anti-CD31 antibody staining of blood vessels in Vhcland Lov-treated tumors. (B,C) Quantification of vessel density and diameter from images as in $A$ ( $n \geq 10$ slices from each of 4 tumors/ condition). (D-I) Blood vessel ultrastructure in tumors from Vhcl- $(D, F, G)$ and Lov-treated $(E, H, I)$ mice. (J) Pericyte coverage of vessels $\left(\mathrm{CD} 31^{+}\right.$, green), detected by nestin staining (red) in Vhcl- and Lov-treated tumors; yellow, double-stained area. (K) Quantification of nestin and CD31 colocalization in $J$. (L,M) FITC-lectin-perfused Vhcl- $(L)$ and Lov-treated $(M)$ mice, co-stained for CD31. (N) Quantification of $\mathrm{CD} 31^{+} /$lectin $^{+}$vessels in $L$ and $M$. In all cases, $n \geq 30$ from at least 3 tumors/condition. $B, C, K, N:{ }^{*} \mathrm{p}<0.05$, **p $<0.01$ two-tailed Student's $t$-test.
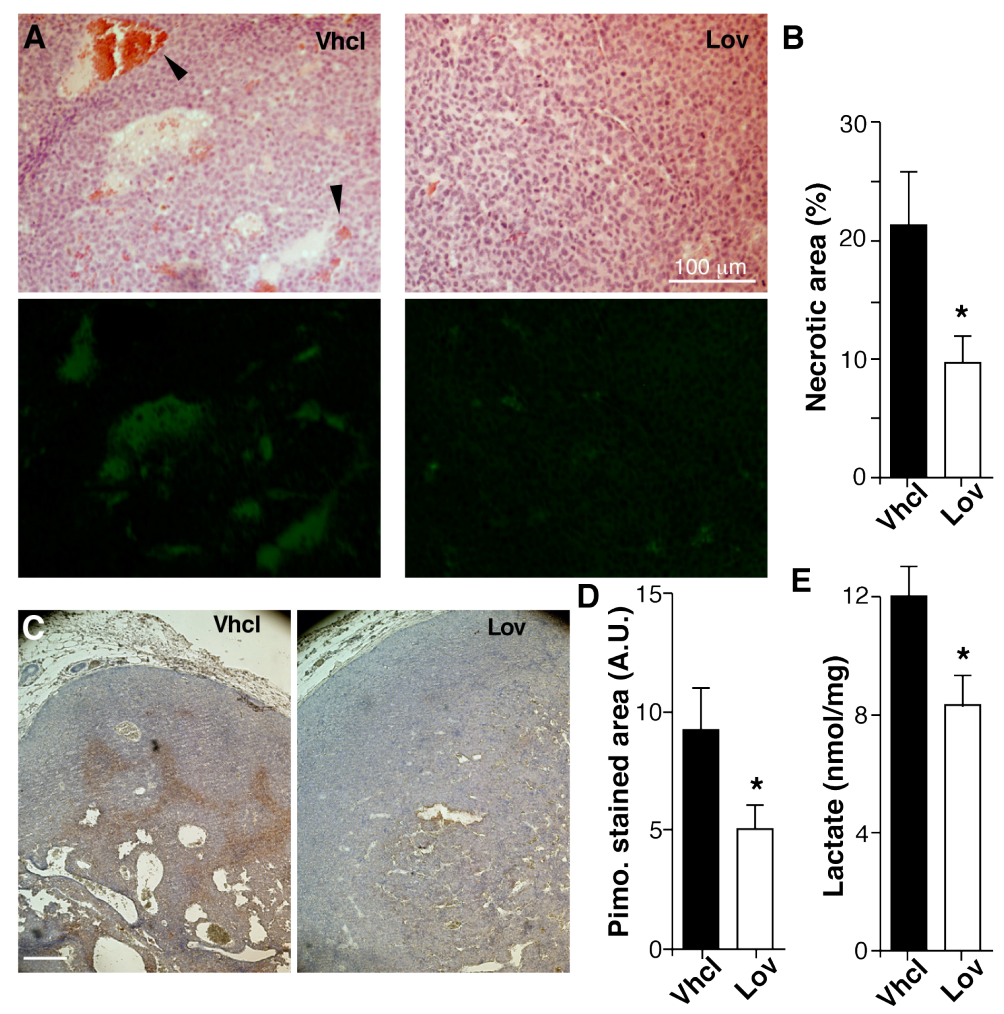

Figure 4: Lovastatin improves Tg-neu tumor oxygenation. (A) Histological sections of necrotic areas in Vhcl- and Lov-treated tumors, hematoxylin/eosin-stained (top) or analyzed for autofluorescence (bottom). Arrowheads indicate "blood lakes". (B) Quantification of necrotic areas in $A$. (C) Pimonidazole staining to detect hypoxic areas. (D) Quantification of pimonidizole-stained area in the sections in $C$. $B, D:\left(n \geq 5\right.$ sections from at least four distinct tumors/group; ${ }^{*} \mathrm{p}<0.05$; Mann-Whitney test). (E) Lactate concentration in Vhcl- and Lov-treated tumors $\left(n=5\right.$ tumors/group; ${ }^{*} \mathrm{p}<0.05$, two-tailed Student's $t$-test). 
larger (Fig. 4D) and more intensely labeled (not shown) in size-matched tumors from Vhcl- compared to Lov-treated mice. Consistent with enhanced tumor oxygenation, Lov treatment significantly reduced lactate levels (Fig. 4E), whose accumulation is linked to glycolytic metabolism in hypoxic tissues (Warburg effect). Lov treatment thus enhanced oxygenation of spontaneous mammary tumors in Tg-neu mice.

\section{Lovastatin downregulates PIGF expression in mammary tumors}

To identify unique gene expression signatures responsible for Lov-induced vascular changes, we performed microarray analyses with mRNA isolated from tumors of Vhcl- and Lov-treated mice $(n=5 /$ group). Genes showing a \pm 2 -fold difference and a p-value $<0.002$ were considered to be differentially regulated by Lov. Based on these criteria, Lov treatment upregulated 39 (Table S1) and downregulated 49 genes (Table S2) compared to Vhcl; none of the differentially regulated genes were significant at a false discovery rate $($ FDR $)<0.25$. Based on their treatment-induced up- or downregulation or on biological significance, we selected 28 genes for assay by quantitative real-time (qRT)-PCR in a set of six independent tumors for each treatment condition (Table S1, S2); 75\% of the upregulated and 95\% of the downregulated genes were validated.

Gene ontology analysis of differentially regulated transcripts predicted a number of biological processes significantly altered by Lov treatment (Fig. 5A, B; FDR $<0.05$ ). Lov-affected processes included oxidation/ reduction, which concurs with the changes in tumor oxygenation, metabolism, including the downregulation of the glycolytic enzyme 6-phosphofructokinase/ fructose-2,6-bisphosphate ( $p f k f b 3)$ gene, as well as the downmodulation of positive regulators of angiogenesis. We found that Lov downregulated the placental growth factor $(p \lg f)$ gene, whose elevation is associated with the abnormalization of tumor vessels [34]. Lov-induced downregulation of PlGF was validated at the mRNA (Table S2) and protein levels (Fig. 5C). VEGF mRNA levels were comparable in Vhcl- and Lov-treated tumors (Fig. 5D), suggesting that the Lov effect was specific for PlGF expression.

To further study the PlGF-producing cell types in the tumor parenchyma, we combined magnetic beads and FACS to isolate the three major cell populations in Tgneu tumors, CD24 $4^{+}$tumor cells (luminal origin), CD $31^{+}$ (endothelial cells) and $\mathrm{CD}^{+} 5^{+}$(hematopoietic cells). Lov treatment reduced PlGF mRNA levels in all three fractions (Fig. 5E), although this tendency was not statistically significant in any case. These results suggest that Lov
A

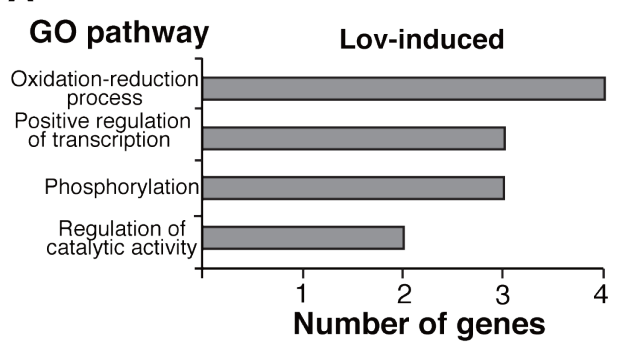

B

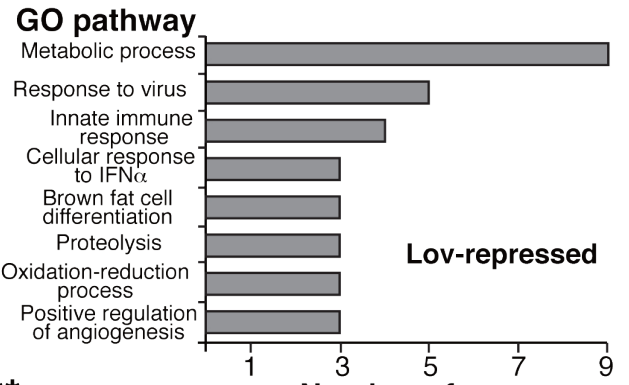

C

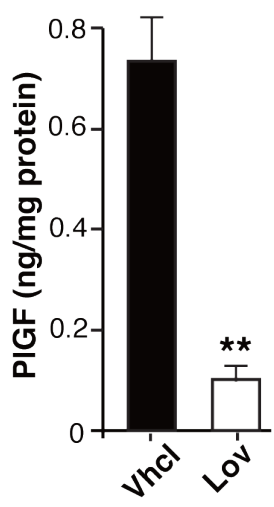

D

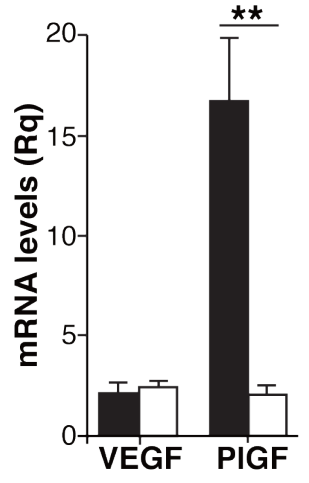

E

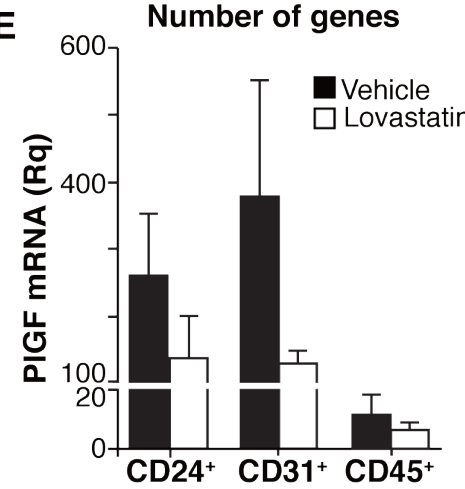

Figure 5: Lovastatin triggers a genetic program that targets angiogenesis, oxidative stress and inflammation. (A,B) Main gene ontology processes significantly induced $(A)$ or repressed $(B)$ by Lov treatment (FDR $<0.05)$. (C) PlGF levels in tumor extracts from Vhcl- or Lov-treated Tg-neu mice. Values show mean \pm SEM of triplicates in one representative experiment of two ( $n=6$ tumors/ group). (D) VEGF and PIGF mRNA levels in Vhcl- or Lov-treated Tg-neu tumors. Relative quantity was calculated using as reference the sample with the lowest VEGF or PlGF mRNA value. Mean $\pm \operatorname{SEM}(n=5)$. (E) PlGF mRNA quantification in CD24 $4^{+}, \mathrm{CD}^{+} 1^{+}$and CD45 cell populations isolated from Vhcl- or Lov-treated tumors $(n=4)$. $C, D, * * \mathrm{p}<0.01$, two-tailed Student's t-test. 
downregulates PlGF by concerted inhibitory activity in the parenchymal and stromal compartments.
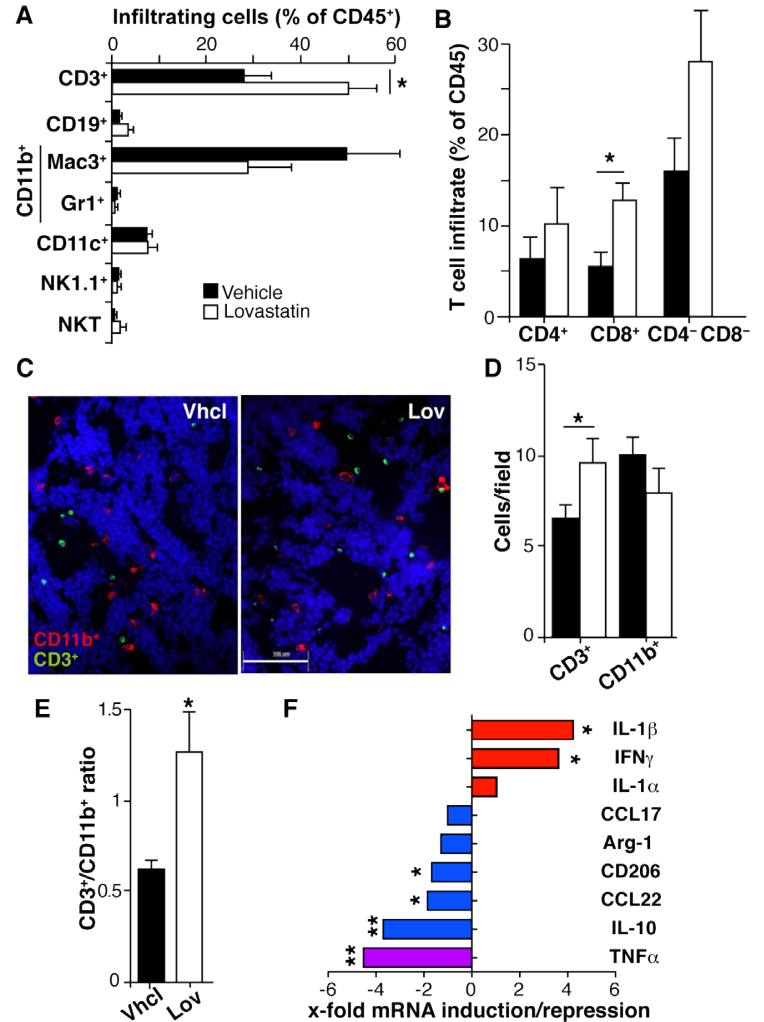

F

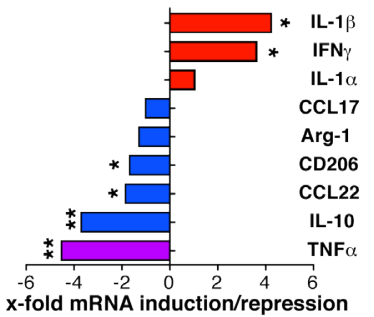

G
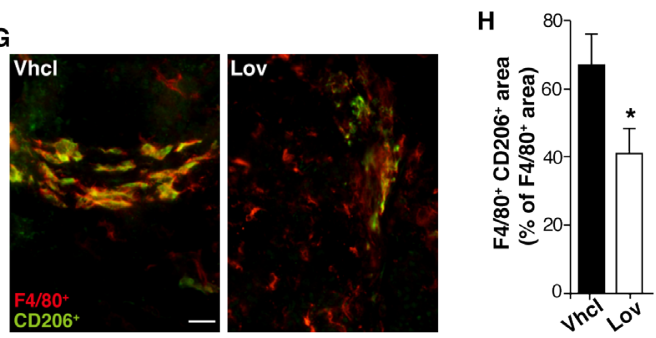

Figure 6: Lovastatin shapes the inflammatory infiltrate and reduces M2-like TAM polarization. (A) Percentage of leukocyte subtypes that infiltrate Vhcl- and Lov-treated Tgneu tumors. (B) Percentage of T lymphocyte subsets in tumors as in $A$. Mean $\pm \operatorname{SEM}$ ( $n=5$ mice/condition). (C) Representative tumor sections stained for CD11b (myeloid cells, red) and CD3 (lymphoid cells, green); bar $=100 \mu \mathrm{m}$. (D) Quantification of myeloid and lymphoid cells from $C$. Mean \pm SEM $(n=10$ images from 2 tumors/group). (E) $\mathrm{CD}^{+} / \mathrm{CD} 11 \mathrm{~b}^{+}$cell ratio for $D$. (F) Lov-mediated induction or repression of mRNA for the indicated M1 (red) and M2 markers (blue) in isolated tumorinfiltrating $\mathrm{CD}^{+} 5^{+}$cells; the M1/M2 marker $\mathrm{TNF} \alpha$ is indicated (violet). Values indicate the relative expression for Lov- and Vhcl-treated tumors, and represent the mean variation in mRNA expression from at least 4 tumors/group. (G) Representative sections from Tg-neu tumors in Vhcl- and Lov-treated mice, stained for the M2 marker CD206 (green) and the macrophage marker F4/80 (red); bar $=20 \mu \mathrm{m}$. (H) Quantification of M2-like TAM $\left(\mathrm{F} 4 / 80^{+} / \mathrm{CD} 206^{+}\right)$in images as in $G(n=20$ images from 3 tumors/group). $B, D, E, F$ and $H, * \mathrm{p}<0.05, * * \mathrm{p}<0.01$, twotailed Student's $t$-test.

\section{Lovastatin shapes the inflammatory infiltrate} towards an anti-tumor phenotype

Our results could explain the Lov effect on the tumor vasculature, but not the reduced tumor multiplicity associated with Lov treatment in Tg-neu mice (Fig. 1G). This prevention of tumorigenesis might be due to Lovinduced changes in inflammation and immune responses, two biological processes markedly affected by Lov treatment (Fig. 5B). We used FACS to analyze infiltration of Vhcl- and Lov-treated tumors by $\mathrm{T}\left(\mathrm{CD}^{+}\right)$and $\mathrm{B}$ cells $\left(\mathrm{CD} 19^{+}\right)$, TAM $\left(\mathrm{Mac}^{+}\right)$, granulocytes $\left(\mathrm{Gr}^{+}\right)$, dendritic $\left(\mathrm{DC}, \mathrm{CD} 11 \mathrm{c}^{+}\right)$, natural killer $\left(\mathrm{NK} 1.1^{+}\right)$and $\mathrm{NK} \mathrm{T}$ cells $\left(\mathrm{NK} 1.1^{+} / \mathrm{CD}^{+}\right)$. Tg-neu tumors in control mice were massively infiltrated by TAM ( $\sim 50 \%$ of $\mathrm{CD} 45^{+}$cells $)$and to a lesser extent by T lymphocytes ( $30 \%$; Fig. 6 A). Lov
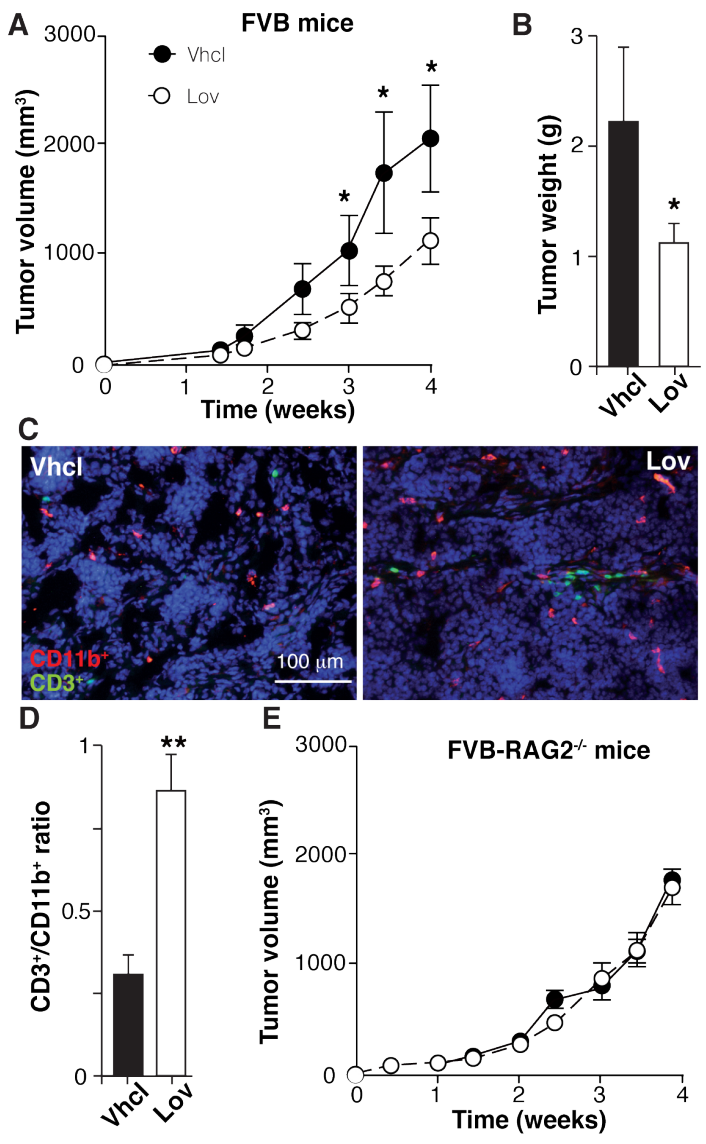

Figure 7: Lovastatin inhibits N202.1A tumor growth in immunocompetent but not in immunodeficient mice. (A) Growth kinetics of N202.1A-induced tumors in immunocompetent Vhcl- or Lov-treated Tg-neu mice. (B) Weight of tumors in $A$ after sacrifice. $A, B$ : Values show mean \pm SEM ( $n=9$ mice/group). (C) Representative sections from tumors in $A$, stained for CD11b (red) and CD3 (green). (D) $\mathrm{CD}^{+} / \mathrm{CD} 1 \mathrm{~b}^{+}$cell ratio in images as in $C(n=6$ images/ group). (E) Growth kinetics of N202.1A tumors implanted in immunodeficient Vhcl- or Lov-treated Rag2 $2^{-/}$mice $(n=8$ mice/ group). $A, B, D, * \mathrm{p}<0.05, * * \mathrm{p}<0.01$, two-tailed Student's $t$-test. 
treatment significantly enhanced infiltration of $\mathrm{T}$ cells compared to TAM (Fig. 6A), particularly $\mathrm{CD}^{+} \mathrm{T}$ cells (Fig. 6B); Treg cell numbers were nonetheless unchanged in Vhcl- and Lov-treated tumors, as determined by FoxP3 mRNA analysis (not shown). Staining of tumor sections confirmed a significant increase in $\mathrm{CD}^{+}$cell infiltration in Lov-treated tumors (Fig. 6C, D), which reversed the T cell/TAM ratio in Vhcl-treated controls (Fig. 6E).

PlGF skews TAM towards a protumor, proangiogenic M2-like phenotype, which triggers angiogenesis and suppresses $\mathrm{T}$ cell-mediated immunity [30]. Since Lov downregulated PlGF in our model (Fig. 5), this treatment might also inhibit M2-like TAM polarization. M2-like TAM have high levels of mannose receptor-1 (MRC1/CD206), arginase-1 (Arg1), IL-10 and chemokines CCL22 and CCL17, whereas anti-tumor M1-like TAM express high interferon (IFN) $\gamma$ and IL- $1 \alpha / \beta$ levels; TNF $\alpha$ marks both M1- and M2-polarized TAM [6].

Analyses of purified tumor-infiltrating $\mathrm{CD} 45^{+}$cells indicated that Lov treatment increased mRNA levels for M1 markers, which was statistically significant for IFN $\gamma$ and IL-1 $\beta$, whereas it downregulated M2-like markers (with significant differences for IL-10, CD206 and CCL22; Fig. 6F). Lov treatment also reduced TNF $\alpha$ mRNA, which concurs with the reduced TAM infiltration in these tumors (Fig. 6F). CD206 ${ }^{+}$TAM number was lower in sections from Lov-treated tumors than those from controls (Fig. 6G, H), again indicating that Lov treatment prevented TAM polarization to the M2-like phenotype. Lov treatment thus increased effector $\mathrm{T}$ cell infiltration and prevented tumor-mediated skewing of TAM, two factors associated with enhanced anti-tumor immunity.

\section{Lovastatin inhibits growth of newly formed tumors only in immunocompetent hosts}

Although Lov elicits a genetic program that fosters antitumor immunity, this treatment did not affect growth kinetics of established Tg-neu tumors (Fig. 1B). Tumor multiplicity was nonetheless reduced (Fig. 1G), suggesting that Lov treatment prevents growth of newly-formed tumors. To mimic this condition, we generated tumors by injecting the syngeneic N202.1A mammary tumor cell line into Tg-neu mice, and Lov treatment was initiated the same day. In this model, Lov administration significantly inhibited tumor growth kinetics as well as final tumor weight (Fig. 7A, B). As for spontaneous mammary tumors, Lov enhanced $\mathrm{T}$ cell infiltration into N202.1A-induced tumors (Fig. 7C), thus increasing the $\mathrm{CD}^{+}$cell/TAM ratio in Lov- compared to Vhcl-treated tumors (Fig. 7D). N202.1A tumor growth kinetics was independent of Lov treatment when cells were implanted in immunodeficient $\mathrm{RAG}^{-/-}$mice (Fig. 7E). This links the adaptive immune system to Lov-mediated inhibition of N202.1A tumor growth.

\section{DISCUSSION}

A tumor-associated inflammatory response boosts incipient neoplasia acquisition of several cancer hallmarks, including angiogenesis and evasion of the immune system [35]. This inflammation is incongruous, since the immune cells responsible for surveillance to prevent nascent tumor development are co-opted to promote them. Reprogramming the tumor-induced inflammatory reaction to "immunological killing" activity could thus present a barrier to tumor formation and progression. Our results indicate that lovastatin is able to induce such reprogramming in spontaneous mammary tumors in Tgneu mice.

Based on studies of numerous acute and chronic inflammation models, the Lov-induced changes in antitumor immunity in Tg-neu mice were unanticipated. A general phenomenon in these models is the Lov-induced shift from Th1 to Th2 responses (reviewed in [14]), which leads to upregulation of immunosuppressive cytokines (such as IL-10) and downregulation of those with antiviral and antitumor activities (such as IFN $\gamma$ ). In Tg-neu mice, however, Lov triggered IL-10 downregulation and IFNg upregulation in $\mathrm{CD} 45^{+}$cells, suggesting a bias toward a Th1 antitumor response. Statins are also reported to reduce Th2 cytokine levels in several models of Th2-mediated inflammation [36, 37]. The statins thus appear to promote a shift in the dominant immune phenotype, from Th1 to Th2 in autoimmune and acute inflammatory conditions, and from Th2 to Th1 in Th2- and tumor-associated inflammation.

Another striking observation in our study was the distinct Lov effect on tumor infiltration by lymphoid and myeloid cells. A consistent result of in vivo statin treatment is a decrease in leukocyte infiltration into inflamed tissue, through mevalonate-dependent and -independent mechanisms [14]. In late-stage Tg-neu tumors, Lov treatment did not alter total numbers of tumor-associated leukocytes (not shown), but selectively enhanced infiltration of cytotoxic $\mathrm{CD}^{+}$and to a lesser extent, of $\mathrm{CD}^{+}$and double-negative $\mathrm{T}$ cells. Lov also induced a consistent, although not significant, reduction of TAM infiltration into tumors; the mechanism that underlies this differential Lov effect on leukocyte infiltration requires further research. Some Lov-targeted molecules involved in transendothelial migration, including certain selectins and leukocyte integrins, participate in lymphoid and myeloid cell diapedesis [38]. Lov might also alter the expression of chemoattractants implicated in the specific infiltration of myeloid or lymphoid cells; for instance, Lov enhances specific infiltration of Treg cells into inflamed footpads by upregulating CCL1 expression in endothelial cells [31] as well as macrophage emigration from atherosclerotic plaques by upregulating CCR7 [39]. Expression profiling in whole tumors showed no Lov-regulated chemokines (Suppl. Table S1, S2). In the $\mathrm{CD} 45^{+}$cell fraction, Lov 
induced downregulation of CCL22, an attractant for Treg cells [40]; however, we found no differences in FoxP3 mRNA levels between Lov- and Vhcl-treated tumors.

Parallel to Lov-induced enhancement of $\mathrm{T}$ cell infiltration, we identified a role for this statin in TAM polarization. Analysis of tumor-infiltrating $\mathrm{CD}^{4} 5^{+}$ leukocytes showed consistent Lov-mediated upregulation of IFN $\gamma$ and IL-1 $\beta$ (M1 markers) and downmodulation of IL-10, CD206 and CCL22 (M2 markers). Moreover, microarray analysis showed Lov-induced downregulation of chitinase 3-like 3 (Chi3l3, Yml), a gene associated to M2 macrophages [41]. This shift in macrophage polarization in $\mathrm{Tg}$-neu tumors contrasts with statin potentiation of alternative M2 macrophage activation in experimental glomerulonephritis models [42] and in the vascular wall of patients with aortic aneurysm [43]. The Lov effect on the TAM phenotype is nonetheless atypical; Lov did not significantly alter IL-1 $\alpha$ or IL-12 levels, which are associated with M1 polarization, or those of Arg1 or CCL17, representative of the M2-like phenotype. It appears that Lov treatment does not cause full TAM reprogramming, but induces a specific genetic signature that reduces TAM differentiation to the pro-tumorigenic M2-like phenotype.

We propose that this M2-to-M1 shift in TAM polarization is mediated largely by Lov-induced downregulation of PIGF, a factor that drives TAM to the M2-like phenotype in tumors [30]. Since PlGF is also involved in aberrant tumor angiogenesis [34, 44], its downregulated expression in Lov-treated tumors might explain the improvement in perfusion and normalization of blood vessel structure. These changes in tumor vasculature indeed underlie the Lov-induced potentiation of the Doxo effect in Tg-neu tumors, as indicated by enhanced tumor parenchyma penetration by the cytotoxin. Based on these findings, we propose that improved vascular function and TAM bias away from the M2-like phenotype are mutual feedback processes, linked through PlGF downmodulation. Nevertheless, other Lov-induced changes in the tumor environment, including increased infiltration of immune effector cells, could contribute to tumor vessel normalization and the reprogramming of protumorigenic TAM $[45,46]$.

An evident question is whether the Lov-induced changes in the inflammatory response are relevant to tumor biology. The combination of M1-biased TAM and the increase in $\mathrm{T}$ cell infiltration could be predicted to enhance antitumor immunity. The growth kinetics of established Tg-neu tumors was nonetheless unaltered by Lov administration, indicating that the effects are insufficient to overcome the immune editing induced by late-stage tumors. In contrast, Lov treatment effectively reduced the number of new spontaneous tumors in Tg-neu mice and inhibited N202.1A tumor growth in immunocompetent, but not in immunodeficient mice. We speculate that these alterations in immune system polarity have a protective function, which would explain the reduced tumor multiplicity in Lov-treated Tg-neu mice. A recent study associated statin use with improved progression-free survival in inflammatory breast cancer patients [47]. The role of statins in the prevention of human cancers is nevertheless debated [22, 48-50]. The partially protective effect of Lov on tumor onset in our murine model, suggests additional tumor mechanisms to bypass this preventive activity.

In summary, our findings indicate that statin treatment elicits a triple program that (1) improves vascular function, hence increasing the penetration of cytotoxic drugs into the tumor parenchyma, (2) enhances $\mathrm{CD}^{+} \mathrm{T}$ cell infiltration into the tumor, thus altering the effector:suppressor cell balance in the tumor stroma, and (3) re-educates TAM to an M1-like phenotype, which might rectify aberrant angiogenesis and create an environment prone to antitumor immunity rather than immune suppression. Our findings support the use of statins in cancer therapy, particularly in combination with immune-based strategies or drugs that induce immunogenic tumor cell death.

\section{MATERIALS AND METHODS}

\section{Cell culture.}

N202.1A mammary cancer cells, derived from a Tg-neu tumor [51], were provided by Dr Vincenzo Bronte (Verona University, Italy) and cultured as described [29].

\section{Tumor induction and drug treatment.}

FVB/N-Tg(MMTVneu) 202Mul/J (Tg-neu) mice were from The Jackson Laboratory and Rag2 $2^{-/}$FVB mice were described elsewhere [52]. Mammary tumors in Tg-neu mice were detected by weekly palpation, after which mice received a dose of Lov $(10 \mathrm{mg} / \mathrm{Kg}$, i.p.; Sigma-Aldrich) or Vhcl (5\% ethanol) 3 times/week for 6 weeks (until killing). Where indicated, Lov treatment was combined with administration of doxorubicin (Doxo; 0.5 or $2.5 \mathrm{mg} / \mathrm{Kg}$, 2 times/week, i.p.; Farmitalia Carlo Erba). N202.1A cells were inoculated s.c. in the right flank of the Tg-neu and Rag2 ${ }^{-/}$mice $\left(0.5 \times 10^{6}\right.$ cells $)$; mice were treated with Lov or Vhcl from the day of cell injection, according to the schedule indicated above. Tumors were measured weekly (Tg-neu) or twice per week (N202.1A) with calipers and volume calculated (width ${ }^{2} \mathrm{x}$ length/2). Live animal experiments were supervised by the CNB Ethics Committee, according to national and European Union guidelines. 


\section{Apoptosis and proliferation analyses in mammary tumors.}

Cryopreserved tumor sections $(10 \mu \mathrm{m})$ were acetone-fixed and stained with anti-phospho-histone $\mathrm{H} 3$ (\#06-570; Millipore), followed by an amplification step with biotinylated secondary antibody and streptavidinCy3; 0.2\% Triton X100 was included in all steps. For TUNEL, sequential tumor sections were fixed with $4 \%$ PFA $\left(20^{\circ} \mathrm{C}\right)$ and stained with the MEBSTAIN Apoptosis kit II (MBL International).

\section{Hypoxia analyses.}

Necrotic areas were determined in sections $(5 \mu \mathrm{m})$ from tumors fixed with neutral-buffered formalin (SigmaAldrich) before paraffin inclusion. Images of hematoxylin/ eosin staining and autofluorescence, used for quantification (ImageJ, NIH), were acquired in a Leica (DM RB) microscope with a DP70 Olympus camera. Hypoxic areas were detected by injecting pimonidazole (Hypoxyprobe-1 Omni kit; Natural Pharmacia International) 30 min before killing mice by cervical dislocation, followed by staining with anti-pimonidazole antibody; hematoxylin was used to counterstain. Images were acquired as above, and quantified with Image-Pro Plus software. Tumor lactate levels were measured with the Lactate Colorimetric Assay kit (Abcam).

\section{Tumor perfusion and blood vessel parameters.}

Tumor-bearing mice were injected (i.v.) with FITClectin $(100 \mu \mathrm{g}$; Vector Laboratories), killed after $10 \mathrm{~min}$, and heart-perfused with 10\% neutral-buffered formalin. Tumors were snap-frozen in tissue freezing medium (OCT; Jung) and $50 \mu \mathrm{m}$ sections stained with anti-CD31 antibody (MEC13.3; BD Biosciences Pharmingen) and analyzed with a Radiance 2100 confocal system (BioRad) on an Axiovent 200 microscope (Zeiss). FITC-lectin ${ }^{+}$ and $\mathrm{CD}_{3} 1^{+}$vessels were determined with NIH-Image $\mathrm{J}$ software. Pericyte coverage was analyzed by staining with anti-CD31 and -nestin antibodies (ab6142; Abcam), and colocalization (Pearson's coefficient) determined with ImageJ (JACoP plug-in). Vessel number and area were quantified from anti-CD31-stained samples using ImageJ.

\section{Scanning electron microscopy (SEM).}

Mice were perfused transcardially with heparinized saline $(50 \mathrm{ml})$ and then with fixative (1\% PFA, 1\% glutaraldehyde in $0.1 \mathrm{M}$ phosphate buffer; $100 \mathrm{ml}$ ) at a constant pressure of $120 \mathrm{~mm} \mathrm{Hg}$. Tumors were dissected out and immersed overnight in the same fixative (at $4 \%$ PFA, 4\% glutaraldehyde). After several washes with PBS, each tumor was cut in half; one remained in the fixative mixture and the other was cryoprotected with $30 \%$ sucrose and frozen by immersion in dry ice-cooled isopentane. Frozen tumor pieces were fractured by striking a sharp blade placed on the specimen surface, then defrosted by immersion in chilled PBS. Frozen and non-frozen samples were postfixed in $1 \%$ osmium tetroxide in PBS $(1 \mathrm{~h})$, rinsed in distilled water, dehydrated in an acetone gradient, which was replaced with liquid carbon dioxide and completely evaporated by critical point drying. To enhance conductivity, samples were graphite-coated in a high vacuum evaporator and then gold-covered in a sputtering device. The vascular network was analyzed in a JEOL JSM 6400 scanning electron microscope.

\section{Doxorubicin quantification.}

Tumor extracts $(100 \mathrm{mg})$ were homogenized in 0.5 $\mathrm{ml}$ PBS with daunorubicin (625 pmol) as internal standard. The homogenate $(0.1 \mathrm{ml})$ was treated with 4 volumes of cold acetone and the mixture kept at $-20^{\circ} \mathrm{C}$ for $150 \mathrm{~min}$. After centrifugation of the precipitated proteins $(16,000 \mathrm{~g}$, $10 \mathrm{~min}$ ), the organic solution was recovered and acetone evaporated under a nitrogen stream. The resulting residue was dissolved in the mobile phase $(0.2 \mathrm{ml})$ and injected $(0.1 \mathrm{ml})$ into an HPLC (Waters 2690 Alliance System) coupled to a Waters 2475 fluorescence detector (480 $\mathrm{nm}$ (excitation) and $560 \mathrm{~nm}$ (emission) wavelengths). Empower Software (Waters Corporation) was used for instrument control and data acquisition and processing. Molecules were separated on a C18 reverse-phase column (Kromasil 100 C18 15 x 0.4 cm, $0.5 \mu \mathrm{m}$; Teknokroma), with a $22: 78$ acetonitrile:water mixture, both containing $0.2 \%$ formic acid and $0.2 \%$ ammonium formate, as the mobile phase. Chromatographic areas corresponding to Doxo were compared to those of daunorubicin, and amounts were calculated from a calibration curve constructed by mixing different Doxo amounts $(5,10,20$, 40 and $80 \mathrm{pmol})$ with a fixed quantity of daunorubicin (40 pmol).

\section{Microarray analyses.}

Total RNA was obtained from Lov- and Vhcltreated Tg-neu tumors ( $n=5 /$ treatment) using TriReagent (Sigma-Aldrich) and further cleaned using RNeasy (Qiagen). RNA quality was confirmed by electropherogram analysis (Agilent 2100 Bioanalyzer). cDNA was synthesized from $4 \mu \mathrm{g}$ total RNA using OneCycle Target Labeling and Control Reagents (Affymetrix) to produce biotin-labeled cRNA. cRNA preparations $(10 \mu \mathrm{g})$ were fragmented $\left(94^{\circ} \mathrm{C}, 35 \mathrm{~min}\right)$ into 35 - to 200 base fragments. Fragmented, biotin-labeled cRNA (10 $\mu \mathrm{g})$ was hybridized to the Affymetrix Mouse Genome 430 2.0 GeneChip array containing 39,000 transcript variants 
from 34,000 well-characterized mouse genes. Each sample was added to a hybridization solution containing $100 \mathrm{mM}$ 2-(N-morpholino)ethanesulfonic acid, $1 \mathrm{M}$ $\mathrm{Na}^{+}$, and $20 \mathrm{mM}$ EDTA with $0.01 \%$ Tween-20, to a final cRNA concentration of $0.05 \mu \mathrm{g} / \mathrm{ml}$. After hybridization $\left(16 \mathrm{~h}, 45^{\circ} \mathrm{C}\right)$, each microarray was washed and stained with streptavidin-phycoerythrin in a Fluidics station 450 (Affymetrix) and scanned at $1.56 \mu \mathrm{m}$ resolution in a GeneChip Scanner 3000 7G System (Affymetrix).

Raw intensity values were summarized and normalized by the Robust Multi-array Analysis (RMA) algorithm [53]. After data processing, each probe was tested for expression changes over replicates using empirical Bayes moderated t-statistics [54]. To control the false discovery rate (FDR), p-values were corrected using the Benjamini-Hochberg method [55]. The FIESTA viewer (http://bioinfogp.cnb.csic.es/tools/FIESTA), developed by J.C. Oliveros (CNB Bioinformatics Core Facility), was used to visualize all microarray results and to evaluate the numerical thresholds applied for selecting differentially expressed genes. Original archives and normalized intensity values are deposited in the Gene Expression Omnibus database (NCBI-GEO; Acc. Code GSE42787, http://www.ncbi.nlm.nih.gov/geo/). Functional analyses of biological processes were determined by Genecodis, which indicates the significantly enriched gene ontology terms in the list of gene targets $[56,57]$.

\section{Quantitative PCR.}

Cell populations from tumors were purified as described [58]. Total RNA from total tumor samples or tumor cell fractions was extracted with Tri-Reagent or with the Easy RNA kit (Qiagen, when recovered cells $\leq 5 \times 10^{5}$ ) and used to synthesize the first cDNA strand (High-capacity cDNA Archive Kit, Applied Biosystems) using random primers. Genes selected from the microarray analysis, and VEGF, cytokines, chemokines, and specific TAM markers were quantified by qRT-PCR in an ABI PRISM 7900HT System (Applied Biosystems) using a SYBR Green-based reaction mix (FluoCycle; EuroClone); $\beta$-actin amplification was used to normalize cDNA in each sample and to calculate $\Delta \mathrm{C}_{\mathrm{t}}$ values. Unless otherwise indicated, relative quantity $(\mathrm{Rq})$ for each gene was calculated as $2^{-\Delta \Delta \mathrm{Ct}}$ relative to the sample with the lowest expression.

\section{ELISA.}

PlGF levels were determined in RIPA (50 mM Tris$\mathrm{HCl}$, pH 8.0, with $150 \mathrm{mM} \mathrm{NaCl}, 1 \mathrm{mM}$ EDTA, 1\% NP40, $0.5 \%$ Na-deoxycholate, $0.1 \%$ SDS) tumor extracts with the mouse PlGF-2 immunoassay (R\&D Systems).

\section{Determination of leukocyte infiltration and TAM polarization.}

Leukocyte infiltration was analyzed in Tg-neu tumors digested $\left(90 \mathrm{~min}, 37^{\circ} \mathrm{C}\right)$ with collagenase $\mathrm{P}(1$ $\mathrm{mg} / \mathrm{ml}$; Roche) and DNase I (100 $\mu \mathrm{g} / \mathrm{ml}$, Roche); cell suspensions were filtered through a $30 \mu \mathrm{m}$ cell strainer and stained with anti-CD45 (clone I3/2.3), -CD19 (1D3), -Mac3, (M3/84), -NK1.1 (PK136) (BD Pharmingen), -CD3 (145-2C11), -CD8 (53-6.7), -CD11b (M1/70), -CD11c (N418) (eBioscience), -CD4 (GK1.5) and -Gr1 (RB6-8C5) (Beckman Coulter) and analyzed by FACS (Cytomics FC500, Beckman Coulter).

Immunohistochemistry was carried out in acetonefixed, cryopreserved tumor sections $(10 \mu \mathrm{m})$ stained with anti-CD3 (Dako), -CD11b (M1/70, Beckman Coulter), -F4/80 (BM8, eBioscience) and -CD206 (MR5D3, Serotec), followed by appropriate secondary antibodies or streptavidin-Cy3 (Jackson ImmunoResearch). Cells were counted and staining area determined with Image J. TAM polarization was quantified as the percentage of $\mathrm{CD} 206^{+}-$ stained area relative to that of $\mathrm{F} 4 / 80^{+}$.

\section{Statistical analysis.}

Data represent mean \pm SEM of replicate values from independent experiments. Statistical significance was calculated with the two-tailed Student's $t$-test or Mann-Whitney test for comparison between two groups. One-way ANOVA with Dunnett post-hoc tests was used for multiple comparisons. Differences were considered statistically significant when $\mathrm{p}<0.05$.

\section{AUTHORS' CONTRIBUTIONS}

EM performed or supervised most of the experiments, LC-R analyzed T cell and TAM infiltration by immunohistochemistry, MT purified tumor cell populations and participated in RTqPCR analyses with LA, IA carried out SEM, AG-M participated in the analysis of leukocyte infiltrate by FACS, JC and GF determined Doxo in tumor samples, EM and SM designed and conceived the study and performed statistical analyses. SM and EM wrote the manuscript. All authors read and approved the final manuscript.

\section{ACKNOWLEDGEMENTS}

We thank V Bronte for the N202.1A cell line, TS Kupper for FVB-RAG2 ${ }^{-1}$ mice, F Ortego for advice on statistics, S Gutiérrez Erlandsson and Y Carrasco for help with image treatment, I López-Vidriero and JM Franco for microarray hybridizations, JC Oliveros and A PascualMontano for microarray and GEOprofile database analysis, the excellent technical assistance of L Gómez with mouse 
experiments, E Gómez-Mariscal and E Senís with some immunostainings, E Dalmau with Doxo quantification, and C Mark for editorial assistance. LC-R receives a FPU fellowship from the Spanish Ministry of Education. This work was funded by the Spanish Ministry of Science and Innovation (SAF2011-24453) and the Comunidad de Madrid (IMMUNOTHERCAN; S2010/BMD-2326) to SM, and the Generalitat de Catalunya (SGR 2009 1072) to JC and GF. The authors have no conflicting financial interests.

\section{REFERENCES}

1. Galon J, Costes A, Sanchez-Cabo F, Kirilovsky A, Mlecnik B, Lagorce-Pages C, Tosolini M, Camus M, Berger A, Wind P, Zinzindohoue F, Bruneval P, Cugnenc PH, Trajanoski Z, Fridman WH and Pages F. Type, density, and location of immune cells within human colorectal tumors predict clinical outcome. Science. 2006; 313: 1960-1964.

2. Lohr J, Ratliff T, Huppertz A, Ge Y, Dictus C, Ahmadi R, Grau S, Hiraoka N, Eckstein V, Ecker R, Korff T, von Deimling A, Unterberg A, Beckhove P and Herold-Mende CC. Effector T-cell infiltration positively impacts survival of glioblastoma patients and is impaired by tumor-derived transforming growth factor-beta. Clin Cancer Res. 2011; 17: 4296-4308.

3. Nelson BH. The impact of T-cell immunity on ovarian cancer outcomes. Immunol Rev. 2008; 222: 101-116.

4. Hiraoka N, Onozato $\mathrm{K}$, Kosuge $\mathrm{T}$ and Hirohashi $\mathrm{S}$. Prevalence of FOXP3 + regulatory T cells increases during the progression of pancreatic ductal adenocarcinoma and its premalignant lesions. Clin Cancer Res. 2006; 12: 5423 5434.

5. Mantovani A, Allavena P, Sica A and Balkwill F. Cancerrelated inflammation. Nature. 2008; 454: 436-444.

6. Mantovani A, Sica A, Allavena P, Garlanda C and Locati M. Tumor-associated macrophages and the related myeloidderived suppressor cells as a paradigm of the diversity of macrophage activation. Hum Immunol. 2009; 70: 325-330.

7. Sonda N, Chioda M, Zilio S, Simonato F and Bronte V. Transcription factors in myeloid-derived suppressor cell recruitment and function. Curr Opin Immunol. 2011; 23: 279-285.

8. Bronner LL, Kanter DS and Manson JE. Primary prevention of stroke. N Engl J Med. 1995; 333: 1392-1400.

9. Ehrenstein MR, Jury EC and Mauri C. Statins for atherosclerosis--as good as it gets? N Engl J Med. 2005; 352: 73-75.

10. del Real G, Jiménez-Baranda S, Mira E, Lacalle RA, Lucas P, Gómez-Moutón C, Alegret M, Peña JM, RodríguezZapata M, Alvarez-Mon M, Martínez-A. C and Mañes S. Statins inhibit HIV-1 infection by down-regulating Rho activity. J Exp Med. 2004; 200: 541-547.

11. Jain MK and Ridker PM. Anti-inflammatory effects of statins: clinical evidence and basic mechanisms. Nat Rev Drug Discov. 2005; 4: 977-987.

12. Greenwood J and Mason JC. Statins and the vascular endothelial inflammatory response. Trends Immunol. 2007; 28: 88-98.

13. Hackam DG, Mamdani M, Li P and Redelmeier DA. Statins and sepsis in patients with cardiovascular disease: a population-based cohort analysis. Lancet. 2006; 367: 413418.

14. Mira E and Mañes S. Immunomodulatory and antiinflammatory activities of statins. Endocr Metab Immune Disord Drug Targets. 2009; 9: 237-247.

15. Kouroumichakis I, Papanas N, Proikaki S, Zarogoulidis $\mathrm{P}$ and Maltezos E. Statins in prevention and treatment of severe sepsis and septic shock. Eur J Intern Med. 2011; 22: 125-133.

16. Weis M, Heeschen C, Glassford AJ and Cooke JP. Statins have biphasic effects on angiogenesis. Circulation. 2002; 105: 739-745.

17. Coimbra M, Banciu M, Fens MH, de Smet L, Cabaj M, Metselaar JM, Storm G and Schiffelers RM. Liposomal pravastatin inhibits tumor growth by targeting cancerrelated inflammation. J Control Release. 2010; 148: 303310 .

18. Wong WW, Dimitroulakos J, Minden MD and Penn LZ. HMG-CoA reductase inhibitors and the malignant cell: the statin family of drugs as triggers of tumor-specific apoptosis. Leukemia. 2002; 16: 508-519.

19. Campbell MJ, Esserman LJ, Zhou Y, Shoemaker M, Lobo M, Borman E, Baehner F, Kumar AS, Adduci K, Marx C, Petricoin EF, Liotta LA, Winters M, Benz S and Benz CC. Breast cancer growth prevention by statins. Cancer Res. 2006; 66: 8707-8714.

20. Garcia-Ruiz C, Morales A and Fernandez-Checa JC. Statins and protein prenylation in cancer cell biology and therapy. Anticancer Agents Med Chem. 2012; 12: 303-315.

21. Freed-Pastor WA, Mizuno H, Zhao X, Langerod A, Moon SH, Rodriguez-Barrueco R, Barsotti A, Chicas A, Li W, Polotskaia A, Bissell MJ, Osborne TF, Tian B, Lowe SW, Silva JM, Borresen-Dale AL, et al. Mutant p53 disrupts mammary tissue architecture via the mevalonate pathway. Cell. 2012; 148: 244-258.

22. Osmak M. Statins and cancer: current and future prospects. Cancer Lett. 2012; 324: 1-12.

23. Feleszko W, Mlynarczuk I, Balkowiec-Iskra EZ, Czajka A, Switaj T, Stoklosa T, Giermasz A and Jakobisiak M. Lovastatin potentiates antitumor activity and attenuates cardiotoxicity of doxorubicin in three tumor models in mice. Clin Cancer Res. 2000; 6: 2044-2052.

24. Swamy MV, Patlolla JM, Steele VE, Kopelovich L, Reddy $\mathrm{BS}$ and Rao CV. Chemoprevention of familial adenomatous polyposis by low doses of atorvastatin and celecoxib given individually and in combination to APCMin mice. Cancer Res. 2006; 66: 7370-7377. 
25. Jakobisiak $M$ and Golab J. Statins can modulate effectiveness of antitumor therapeutic modalities. Med Res Rev. 2010; 30: 102-135.

26. Chen Y, Zhang S, Peng G, Yu J, Liu T, Meng R, Li Z, Zhao $\mathrm{Y}$ and $\mathrm{Wu} \mathrm{G}$. Endothelial $\mathrm{NO}$ synthase and reactive oxygen species mediated effect of simvastatin on vessel structure and function: pleiotropic and dose-dependent effect on tumor vascular stabilization. Int J Oncol. 2013; 42: 13251336.

27. Boucher K, Siegel CS, Sharma P, Hauschka PV and Solomon KR. HMG-CoA reductase inhibitors induce apoptosis in pericytes. Microvasc Res. 2006; 71: 91-102.

28. Lustgarten J, Dominguez AL and Cuadros C. The CD8+ T cell repertoire against Her-2/neu antigens in neu transgenic mice is of low avidity with antitumor activity. Eur $\mathrm{J}$ Immunol. 2004; 34: 752-761.

29. González-Martín A, Gómez L, Lustgarten J, Mira E and Mañes S. Maximal T Cell-Mediated Antitumor Responses Rely upon CCR5 Expression in Both CD4+ and CD8+ T Cells. Cancer Res. 2011; 71: 5455-5466.

30. Rolny C, Mazzone M, Tugues S, Laoui D, Johansson I, Coulon C, Squadrito ML, Segura I, Li X, Knevels E, Costa S, Vinckier S, Dresselaer T, Akerud P, De Mol M, Salomaki $\mathrm{H}$, et al. HRG inhibits tumor growth and metastasis by inducing macrophage polarization and vessel normalization through downregulation of PlGF. Cancer Cell. 2011; 19: 31-44.

31. Mira E, León B, Barber DF, Jiménez-Baranda S, Goya I, Almonacid L, Marquez G, Zaballos A, Martínez-A. C, Stein $\mathrm{JV}$, Ardavin C and Mañes S. Statins induce regulatory T cell recruitment via a CCL1 dependent pathway. J Immunol. 2008; 181: 3524-3534.

32. Manzur M, Hamzah $J$ and Ganss R. Modulation of $G$ protein signaling normalizes tumor vessels. Cancer Res. 2009; 69: 396-399.

33. Mazzone M, Dettori D, Leite de Oliveira R, Loges S, Schmidt T, Jonckx B, Tian YM, Lanahan AA, Pollard P, Ruiz de Almodovar C, De Smet F, Vinckier S, Aragones J, Debackere K, Luttun A, Wyns S, et al. Heterozygous deficiency of PHD2 restores tumor oxygenation and inhibits metastasis via endothelial normalization. Cell. 2009; 136: 839-851.

34. Fischer C, Jonckx B, Mazzone M, Zacchigna S, Loges S, Pattarini L, Chorianopoulos E, Liesenborghs L, Koch M, De Mol M, Autiero M, Wyns S, Plaisance S, Moons L, van Rooijen N, Giacca M, et al. Anti-PlGF inhibits growth of $\operatorname{VEGF}(\mathrm{R})$-inhibitor-resistant tumors without affecting healthy vessels. Cell. 2007; 131: 463-475.

35. Hanahan D and Weinberg RA. Hallmarks of cancer: the next generation. Cell. 2011; 144: 646-674.

36. McKay A, Leung BP, McInnes IB, Thomson NC and Liew FY. A novel anti-inflammatory role of simvastatin in a murine model of allergic asthma. J Immunol. 2004; 172: 2903-2908.
37. Zeki AA, Franzi L, Last J and Kenyon NJ. Simvastatin inhibits airway hyperreactivity: implications for the mevalonate pathway and beyond. Am J Respir Crit Care Med. 2009; 180: 731-740.

38. Silveira AA, Dominical VM, Lazarini M, Costa FF and Conran N. Simvastatin abrogates inflamed neutrophil adhesive properties, in association with the inhibition of Mac-1 integrin expression and modulation of Rho kinase activity. Inflamm Res. 2013; 62: 127-132.

39. Feig JE, Shang Y, Rotllan N, Vengrenyuk Y, Wu C, Shamir R, Torra IP, Fernandez-Hernando C, Fisher EA and Garabedian MJ. Statins promote the regression of atherosclerosis via activation of the CCR7-dependent emigration pathway in macrophages. PLoS One. 2011; 6: e28534.

40. Maruyama T, Kono K, Izawa S, Mizukami Y, Kawaguchi Y, Mimura K, Watanabe M and Fujii H. CCL17 and CCL22 chemokines within tumor microenvironment are related to infiltration of regulatory $\mathrm{T}$ cells in esophageal squamous cell carcinoma. Dis Esophagus. 2010; 23: 422-429.

41. Sica A and Mantovani A. Macrophage plasticity and polarization: in vivo veritas. J Clin Invest. 2012; 122: 787 795 .

42. Fujita E, Shimizu A, Masuda Y, Kuwahara N, Arai T, Nagasaka S, Aki K, Mii A, Natori Y, Iino Y, Katayama $\mathrm{Y}$ and Fukuda Y. Statin attenuates experimental antiglomerular basement membrane glomerulonephritis together with the augmentation of alternatively activated macrophages. Am J Pathol. 2010; 177: 1143-1154.

43. van der Meij E, Koning GG, Vriens PW, Peeters MF, Meijer CA, Kortekaas KE, Dalman RL, van Bockel JH, Hanemaaijer R, Kooistra T, Kleemann R and Lindeman JH. A clinical evaluation of statin pleiotropy: statins selectively and dose-dependently reduce vascular inflammation. PLoS One. 2013; 8: e53882.

44. Hilfenhaus G, Gohrig A, Pape UF, Neumann T, Jann H, Zdunek D, Hess G, Stassen JM, Wiedenmann B, Detjen K, Pavel $\mathrm{M}$ and Fischer C. Placental growth factor supports neuroendocrine tumor growth and predicts disease prognosis in patients. Endocr Relat Cancer. 2013; 20: 305319.

45. Lewis CE and Pollard JW. Distinct role of macrophages in different tumor microenvironments. Cancer Res. 2006; 66: 605-612.

46. DeNardo DG, Andreu P and Coussens LM. Interactions between lymphocytes and myeloid cells regulate proversus anti-tumor immunity. Cancer Metastasis Rev. 2010; 29: 309-316.

47. Brewer TM, Masuda H, Liu DD, Shen Y, Liu P, Iwamoto T, Kai K, Barnett CM, Woodward WA, Reuben JM, Yang P, Hortobagyi GN and Ueno NT. Statin use in primary inflammatory breast cancer: a cohort study. Br J Cancer. 2013; 109: 318-324.

48. Friis S, Poulsen AH, Johnsen SP, McLaughlin JK, Fryzek 
JP, Dalton SO, Sorensen HT and Olsen JH. Cancer risk among statin users: a population-based cohort study. Int J Cancer. 2005; 114: 643-647.

49. Murtola TJ, Tammela TL, Maattanen L, Huhtala H, Platz EA, Ala-Opas M, Stenman UH and Auvinen A. Prostate cancer and PSA among statin users in the Finnish prostate cancer screening trial. Int J Cancer. 2010; 127: 1650-1659.

50. Ferris JS, McCoy L, Neugut AI, Wrensch M and Lai R. HMG CoA reductase inhibitors, NSAIDs and risk of glioma. Int J Cancer. 2012; 131: E1031-1037.

51. Nanni P, Pupa SM, Nicoletti G, De Giovanni C, Landuzzi L, Rossi I, Astolfi A, Ricci C, De Vecchi R, Invernizzi AM, Di Carlo E, Musiani P, Forni G, Menard S and Lollini PL. p185(neu) protein is required for tumor and anchorageindependent growth, not for cell proliferation of transgenic mammary carcinoma. Int J Cancer. 2000; 87: 186-194.

52. Murphy JE, Morales RE, Scott J and Kupper TS. IL-1 alpha, innate immunity, and skin carcinogenesis: the effect of constitutive expression of IL-1 alpha in epidermis on chemical carcinogenesis. J Immunol. 2003; 170: $5697-$ 5703.

53. Gautier L, Cope L, Bolstad BM and Irizarry RA. Affy-analysis of Affymetrix GeneChip data at the probe level. Bioinformatics. 2004; 20: 307-315.

54. Smyth GK. Linear models and empirical bayes methods for assessing differential expression in microarray experiments. Stat Appl Genet Mol Biol. 2004; 3: Article3.

55. Benjamini $\mathrm{Y}$ and Hochberg $\mathrm{Y}$. Controling the false discovery rate: a practical and powerful approach to multiple testing. J R Statist Soc B. 1995; 57: 289-300.

56. Nogales-Cadenas R, Carmona-Saez P, Vazquez M, Vicente C, Yang X, Tirado F, Carazo JM and Pascual-Montano A. GeneCodis: interpreting gene lists through enrichment analysis and integration of diverse biological information. Nucleic Acids Res. 2009; 37: W317-322.

57. Carmona-Saez P, Chagoyen M, Tirado F, Carazo JM and Pascual-Montano A. GENECODIS: a web-based tool for finding significant concurrent annotations in gene lists. Genome Biol. 2007; 8: R3.

58. Tardáguila M, Mira E, Garcia-Cabezas MA, Feijoo AM, Quintela-Fandino M, Azcoitia I, Lira SA and Mañes S. CX3CL1 Promotes Breast Cancer via Transactivation of the EGF Pathway. Cancer Res. 2013; 73: 4461-4473. 